\title{
Role of Vasoactive Intestinal Polypeptide in the Internal Anal Sphincter Relaxation of the Opossum
}

\author{
Samuel Nurko and Satish Rattan \\ Harvard Digestive Diseases Center, Charles A. Dana Research Institute and Thorndike Laboratory, Division of Gastroenterology, \\ Department of Medicine, Beth Israel Hospital, Combined Program in Gastroenterology and Nutrition, Children's Hospital \\ and Harvard Medical School, Boston, Massachusetts 02215
}

\begin{abstract}
The nature of the inhibitory neurotransmitter responsible for internal anal sphincter (IAS) relaxation in response to rectoanal reflex is not known. The objective of the present investigation was to examine the role of VIP in IAS relaxation in response to the rectoanal reflex in intact opossums with the use of VIP antagonists, [4CI-D-Phe ${ }^{6}, \mathrm{Leu}^{17}$ ] VIP and (N-Ac$\mathrm{Tyr}^{1}, \mathrm{D}-\mathrm{Phe}^{2}$ )-GRF (1-29)- $\mathrm{NH}_{2}$. Intraluminal pressures from the sphincter were monitored using low-compliance, continuously perfused catheters. VIP and the antagonists were administered close-intraarterially. The responses to VIP, rectoanal reflex, sacral nerve stimulation, and local intramural stimulation were examined before and after the VIP antagonists. The present studies in intact animals show: (a) VIP causes a dose-dependent fall in the IAS pressures by a direct action at the IAS smooth muscle; (b) VIP antagonists selectively and significantly antagonized the inhibitory action of VIP; and (c) VIP antagonists caused significant antagonism of the IAS relaxation caused by rectoanal reflex and the other neural stimuli. The antagonism of the IAS relaxation by the VIP antagonists, depending upon the volume of rectal distension used, ranged from $40 \%$ to $62 \%(P<0.05)$. From these results, we conclude that VIP acts as an inhibitory neurotransmitter for IAS relaxation during the rectoanal reflex.
\end{abstract}

\section{Introduction}

It has been previously shown that internal anal sphincter (IAS) ${ }^{1}$ relaxation is mediated through the release of a noncholinergic, nonadrenergic inhibitory neurotransmitter (1-5). Such noncholinergic, nonadrenergic nerves play a significant role in the relaxation of a variety of smooth muscle tissues (6,

Address reprint requests to Dr. Rattan, Division of Gastroenterology, Department of Medicine, Beth Israel Hospital, 330 Brookline Avenue, Boston, MA 02215.

Received for publication 7 May 1987 and in revised form 23 November 1987.

1. Abbreviations used in this paper: $\mathrm{D}_{50}$, dose producing $50 \%$ of the maximal response; EFS, electrical field stimulation; GRF analogue, $\left(N-A c-T y r^{1}, \mathrm{D}-\mathrm{Phe}^{2}\right)$-GRF (1-29)-NH $\mathrm{NH}_{2}$; IAS, internal anal sphincter; IASP, internal anal sphincter pressure; LES, lower esophageal sphincter; MED, maximal effective dose; PHI, peptide histidine isoleucine; TTX, tetrodotoxin; VIP, vasoactive intestinal polypeptide; VIP analogue, [4CI-D-Phe ${ }^{6}$, $\mathrm{Leu}^{17}$ ] VIP.

J. Clin. Invest.

(C) The American Society for Clinical Investigation, Inc.

$0021-9738 / 88 / 04 / 1146 / 08 \$ 2.00$

Volume 81, April 1988, 1146-1153
7). However, the exact nature of the inhibitory neurotransmitter responsible for the relaxation of these smooth muscle tissues and IAS relaxation is not known. It has been suggested that vasoactive intestinal polypeptide (VIP) acts as a neurotransmitter in certain systems (8-13). Previous in vivo and in vitro studies in the lower esophageal sphincter (LES) $(11,14)$ and in vitro studies in the IAS (3) using VIP antiserum have suggested that VIP may play a role in IAS relaxation. However, studies using newly discovered VIP antagonists $(15,16)$ to examine the participation of VIP as an inhibitory neurotransmitter have not been performed in vivo or in vitro for any smooth muscle including the IAS.

The aim of the present investigation was to examine the possibility of VIP as a noncholinergic, nonadrenergic inhibitory nerotransmitter responsible for the relaxation of the internal anal sphincter in response to the rectoanal reflex (mimicked by rectal balloon distension).

\section{Methods}

Animal preparation. Studies were performed on 23 opossums (Didelphis virginiana) of either sex weighing between 1.6 and $2.8 \mathrm{~kg}$ with a mean of $2.1 \mathrm{~kg}$. The opossum was chosen as the animal model for a number of reasons. The high pressures in the anal canal in this animal species are primarily due to IAS smooth muscle (17). The detailed studies of myenteric (18) and submucosal (19) plexuses of the gut have been carried out in the opossum. The animals were fasted overnight but allowed free access to water. On the day of the experiment each animal was initially anesthetized with pentobarbital sodium $(40 \mathrm{mg} / \mathrm{kg}$ intraperitoneally) and then restrained supine on an animal board equipped with a water circulating heat pad (model K-20, GormanRupp Industries Div., Belleville, $\mathrm{OH}$ ) to maintain the body temperature at $36^{\circ} \mathrm{C}$. Either femoral vein was cannulated to provide central venous access for intravenous (i.v.) administration of different agents. The left femoral artery was cannulated and the catheter advanced $\sim 10 \mathrm{~cm}$ (just cephalad to the aortic bifurcation) for monitoring the blood pressure and localized intraarterial (i.a.) administration of various agents. The position of the i.a. cannula was confirmed at the end of the experiment. Subsequent anesthesia was provided with $\alpha$-chloralose (70-200 mg i.v.) as needed.

The animals were intubated with a cuffed endotracheal tube (3.0 $\mathrm{mm}$ i.d.; $4.3 \mathrm{~mm}$ o.d.), and placed on an artificial ventilator (model 661, Harvard Apparatus Co., Millis, MA) at 20 strokes/min. The tidal volume was determined from the Harvard Apparatus ventilation nomogram based on body weight.

The animals were then turned to a prone position. A middorsal incision was made over the pelvisacral region, and the lateral paraspinous muscles were dissected and retracted to expose the sacroiliac joint and sacrum. As described previously (2), the overhanging portion of the pars lateralis and the sacroiliac joint were resected to expose the sacral nerve roots as they emerged from the sacral foramina. Bipolar, silver-silver chloride hook stimulating electrodes were placed in contact with the fourth sacral nerve root to provide sacral nerve stimulation. Bipolar stainless steel needle electrodes $(2 \mathrm{~mm}$ apart) were in- 
serted into the muscularis of the distal anal canal, $\sim 1 \mathrm{~cm}$ from the anal verge, to provide local intramural stimulation. A balloon constructed as part of the catheter assembly was placed in the rectum as described below. Inflation of the balloon was intended to produce rectal distension. Pancuronium bromide (Organon Inc., W. Orange, NJ) $1 \mathrm{mg} / \mathrm{kg}$ i.v. was administered to eliminate the electromyographic activity of the external anal sphincter (17).

Intraluminal pressure measurements. A specially designed, sixchannel manometry catheter assembly continuously perfused with bubble-free water through a low compliance, pneumohydraulic valve system was used to record internal anal sphincter pressures. The catheter assembly consisted of six polyvinyl tubes (i.d. $0.7 \mathrm{~mm}$, o.d. 1.3 $\mathrm{mm}$; Insultab, Woburn, MA) arranged around a central polyvinyl tube (i.d. $1.6 \mathrm{~mm}$, o.d. $2.4 \mathrm{~mm}$ ) to which an inflatable balloon constructed from a finger cot was attached. The assembly provided a linear array of six side-hole openings situated at $0.6-\mathrm{cm}$ intervals with an inflatable balloon attached $2 \mathrm{~cm}$ beyond the distal port. The total outside diameter of the assembly was $4.7 \mathrm{~mm}$. The catheter was positioned so that the pressures from the distal rectum and the entire length of the anal canal could be recorded simultaneously. A pull-through was performed until the highest pressure zone of the IAS was identified. The rectal balloon could be inflated with varying volumes of air without disturbing the position of the catheter assembly. For the sake of uniformity, resting sphincter pressures from the top of the rhythmic fluctuations were recorded in the zone that gave the highest pressures. Pressures were recorded on a Beckman Dynograph recorder (model R711, Beckman Instruments Inc., Schiller Park, IL) using Statham transducers. The pressure dynamics of the perfused catheters were such that abrupt occlusion of the catheter tip produced a pressure rise of $200 \mathrm{mmHg}$ in $0.1 \mathrm{~s}$. The baselines were set at atmospheric pressure. Details of the catheter assembly and the procedure for recording pressure have been described before (17).

Stimulus and drug administration. Baseline responses to isoproterenol hydrochloride (Winthrop Laboratories, New York; mol wt 211.24) $4.8-9.5 \times 10^{-9} \mathrm{~mol} / \mathrm{kg}(1-2 \mu \mathrm{g} / \mathrm{kg})$ administered i.a. were obtained. Control responses of the fall in internal anal sphincter pressures (IASP) by sacral nerve stimulation from 0.5 to $20 \mathrm{~Hz}(5 \mathrm{~mA}$; 0.5-ms pulse duration; 2 -s train) and local intramural stimulation with 20 and $40 \mathrm{~Hz}$ (5 mA; 0.5-ms pulse duration; 2-s train) were obtained using a stimulator (model S1 1A, Grass Instrument Co., Quincy, MA). Inhibitory responses to rectal balloon distension on IAS were obtained by inflating the rectal balloon with volumes of $2-15 \mathrm{ml}$ of air for $8 \mathrm{~s}$.

Dose-response curves were obtained after the i.a. administration of vasoactive intestinal polypeptide (VIP) (VIP porcine sequence; Sigma Chemical Co., St. Louis, MO; mol wt 3,326) in doses ranging from 1.1 $\times 10^{-12}$ to $7.2 \times 10^{-9} \mathrm{~mol} / \mathrm{kg}$.

The influence of i.a. administration of the neurotoxin tetrodotoxin (TTX) (Calbiochem-Behring Corp., San Diego, CA; mol wt 319.28) on the VIP dose-response curve was then examined. The initial dose was $1.6 \times 10^{-8} \mathrm{~mol} / \mathrm{kg}(5 \mu \mathrm{g} / \mathrm{kg})$, and it was then repeated as necessary until the rectoanal reflex response to balloon distension was abolished. In all the experiments where TTX was used, the animals were provided with cardiovascular support with a continuous i.v. infusion of lactated Ringer's at $9 \mathrm{ml} / \mathrm{h}$. The above-mentioned doses of VIP were administered again once the rectal distension-induced IAS relaxation was abolished.

The effects of two VIP antagonists, VIP analogue, [4CI-D$\mathrm{Phe}^{6}{ }^{6}$ Leu $^{17}$ ] VIP (a generous gift from Dr. J. Rivier of the Peptide Biology Laboratory of the Salk Institute, San Diego, CA; mol wt 3,342.09) (15) and GRF analogue, ( $N$-Ac-Tyr ${ }^{1}$,D-Phe ${ }^{2}$ )-GRF (1-29)$\mathrm{NH}_{2}$ (Peninsula Laboratories, Inc., Belmont, CA; mol wt 3,476.3) (16) on IAS relaxation were investigated. Both antagonists were administered in incremental doses until the fall in IASP caused by near $D_{50}$ of VIP was significantly antagonized. At that point a constant i.a. infusion of the antagonist was started. After VIP antagonism was achieved, IASP responses to isoproterenol, VIP, sacral nerve stimulation, rectal balloon distension, and local intramural stimulation were repeated.

In one series of experiments, after obtaining significant VIP antago- nism with ( $N$-Ac-Tyr ${ }^{1}$,D-Phe $\left.{ }^{2}\right)-G R F(1-29)-\mathrm{NH}_{2}$, and after administration of the above-mentioned stimuli, the dose of the antagonist was increased fourfold, and the stimuli were repeated. The purpose of this experiment was to determine if the GRF analogue acted as a competitive antagonist. Such experiments were not performed with [4CI-D$\left.\mathrm{Phe}^{6}, \mathrm{Leu}^{17}\right]$ VIP because of the limited amount of the antagonist available.

In another series of experiments baseline responses to VIP, 1.5 $\times 10^{-10} \mathrm{~mol} / \mathrm{kg}$, isoproterenol hydrochloride, $2.9 \times 10^{-10} \mathrm{~mol} / \mathrm{kg}$, adenosine (Calbiochem-Behring Corp.; mol wt 267.2), $7.9 \times 10^{-7}$ $\mathrm{mol} / \mathrm{kg}$, and peptide histidine isoleucine (PHI) (Peninsula Laboratories, Inc.; mol wt 2,995.85), $6.0 \times 10^{-10} \mathrm{~mol} / \mathrm{kg}$ administered i.a. were obtained, before and after the administration of the VIP antagonists.

In vitro experiments. In another series of experiments some in vitro studies were performed to examine the possibility of VIP as an inhibitory neurotransmitter in the neurally mediated relaxation of isolated smooth muscle strips of the IAS of the opossum. For these experiments, standard methodology for recording resting tension and its changes in response to electrical field stimulation (EFS) and VIP was employed (3). The changes in the IAS tension were expressed on a percentile basis. In this series of experiments, the control responses to $\operatorname{EFS}(50 \mathrm{~V}, 2 \mathrm{~ms}$ for 4-s train) at different frequencies $(0.5-10 \mathrm{~Hz})$ and different doses of VIP $\left(1.0 \times 10^{-7}\right.$ to $\left.1.0 \times 10^{-6} \mathrm{M}\right)$ on the resting tension of the IAS strips were examined. The responses to these stimuli were then repeated in the presence of [4CI-D-Phe ${ }^{6}$, Leu $^{17}$ ] VIP $(30 \mu \mathrm{M})$ and $\left(N-A_{C}-T_{y r}{ }^{1}, D-P_{1}{ }^{2}\right)$-GRF (1-29)-NH ${ }_{2}(10 \mu \mathrm{M})$. The doses of both antagonists were chosen on the bases of previous experiments by other investigators studies in in vitro $(15,16)$.

The i.a. catheters, syringes used for injection, and vials containing different peptide solutions and muscle baths were all rinsed with $2.5 \%$ bovine serum albumin before use to avoid binding of peptides to polyvinyl tubing, plastic, and glassware. All agents employed in the study were dissolved in physiologic saline. The i.a. or i.v. administration of different volumes of physiological saline produced no significant change either on the resting tone of the IAS or in response to any stimuli.

Data analysis. All results are expressed as mean \pm SE of different observations. Changes in IASP and tensions are expressed on percentile as well as absolute bases. The statistical analysis was performed using one-tail $t$ tests or multivariate analysis where appropriate (20).

\section{Results}

Effect of VIP on the resting internal anal sphincter. Intraarterial administration of VIP produced a dose-dependent fall in IASP (Fig. 1). The threshold dose $\left(1.1 \times 10^{-12} \mathrm{~mol} / \mathrm{kg}\right)$ of VIP produced $19.2 \pm 3.7 \%$ fall (from $61.2 \pm 2.9$ to $48.5 \pm 2.0 \mathrm{mmHg}$ ) in IASP. The maximal effective dose (MED) was $1.8 \times 10^{-9}$ $\mathrm{mol} / \mathrm{kg}$, which produced a fall in IASP of $90.6 \pm 0.7 \%$ (from

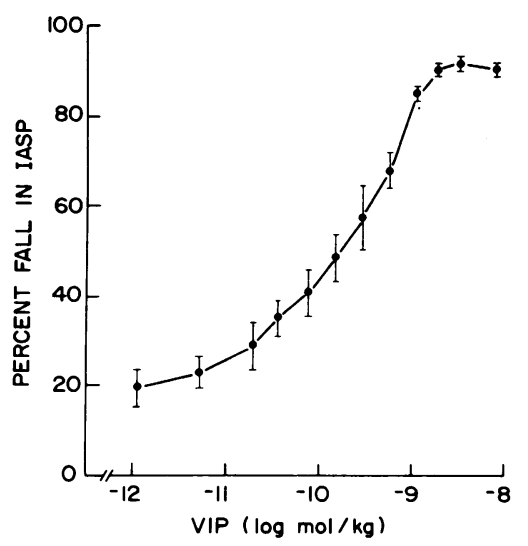

Figure 1. Effect of different doses of VIP on the percent fall in IASP. The percent fall in IASP by VIP was dose dependent. The threshold dose for VIP in causing fall in IASP was $1.1 \times 10^{-12} \mathrm{~mol} / \mathrm{kg}$ and the MED was 1.8 $\times 10^{-9} \mathrm{~mol} / \mathrm{kg}$. The $D_{50}$ was $1 \times 10^{-10} \mathrm{~mol} / \mathrm{kg}$. 


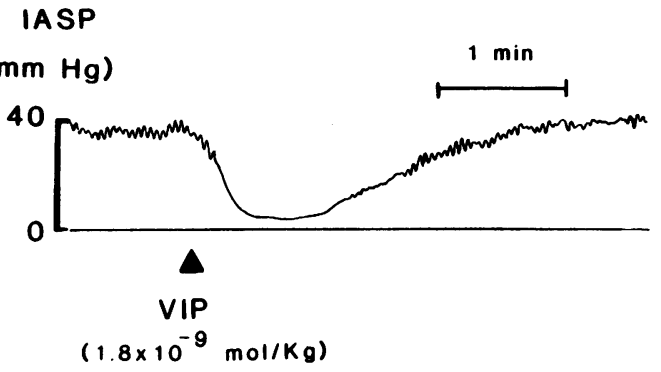

Figure 2. An example showing the effect of MED of VIP administered i.a. on the IASP.

$58.5 \pm 1.6$ to $5.4 \pm 0.3 \mathrm{mmHg}$ ) ( $n=10$ in five animals). The $\mathrm{D}_{50}$ for VIP (a dose causing 50\% of the maximal fall in IASP) was $1.0 \times 10^{-10} \mathrm{~mol} / \mathrm{kg}$. The latency of onset of fall in IASP and the duration of action with the MED of VIP were $8.0 \pm 0.8$ and $111.5 \pm 12.0 \mathrm{~s}$, respectively.

Fig. 2 is a typical example showing the inhibitory effect of the MED of VIP on the resting IAS pressure.

Influence of TTX on the inhibitory response of VIP on the $I A S P$. TTX administered in the doses that abolished the fall in IASP in response to rectal distension failed to modify the fall in IASP caused by VIP. The fall in IASP caused by the MED of VIP in the control experiments was $91.5 \pm 1.2 \%$ (from $58.1 \pm 2.7$ to $5.0 \pm 0.8 \mathrm{mmHg}$ ), and after TTX, it was $91.6 \pm 1.2 \%$ (from $47.0 \pm 3.2$ to $3.8 \pm 0.5 \mathrm{mmHg}$ ). These values were not signifcantly different $(P>0.05 ; n=6$ in three animals). The entire dose-response curve with VIP showing a fall in IASP obtained during control experiments was compared with the one obtained after TTX administration by polynomial comparison. No significant difference between the two curves was found $(P$ $>0.05$; Fig. 3 ).

Influence of VIP antagonist, [4CI-D-Phe ${ }^{6}$, Leu $\left.^{17}\right]$ VIP on fall in IASP caused by VIP and other agonists. In the initial experiments the influence of different doses of [4CI-D-Phe ${ }^{6}, \mathrm{Leu}^{17}$ ] VIP $\left(1.7 \times 10^{-9}\right.$ to $\left.2.3 \times 10^{-7} \mathrm{~mol} / \mathrm{kg}\right)$ on the fall in IASP caused by VIP was examined. It was observed that this VIP analogue was required in the dose of $2.3 \times 10^{-7} \mathrm{~mol} / \mathrm{kg}$ i.a. to

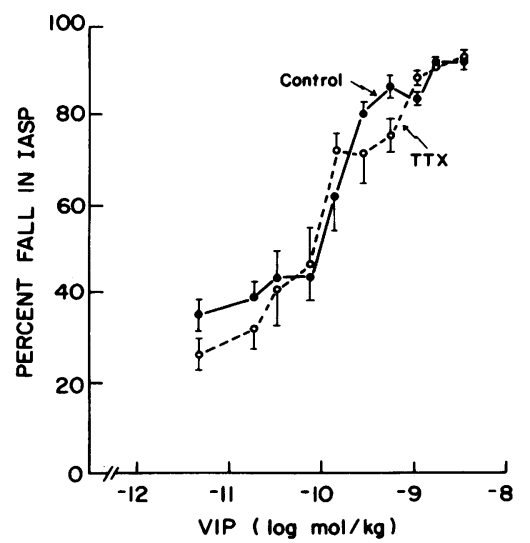

Figure 3. Influence of the neurotoxin TTX on the fall in the resting IASP caused by different doses of VIP. The figure shows the comparison of dose-response curves obtained with VIP before and after TTX in the same animals. The comparison of two curves revealed that TTX exerted no significant effect on the fall in IASP caused by VIP $(P$ $>0.05 ; n=6$ in three animals, two observations in each animal at each dose level). significantly antagonize the inhibitory effect of VIP on IAS. The antagonism of VIP responses on IAS by the single bolus of VIP analogue lasted for $\sim 30 \mathrm{~min}$. In the longer protocols, when needed, the duration of action of [4CI-D-Phe ${ }^{6}, \mathrm{Leu}^{17}$ ] VIP could be prolonged by a constant i.a. infusion $\left(2.8 \times 10^{-9}\right.$ $\mathrm{mol} / \mathrm{kg} / \mathrm{min}$ ) of the antagonist.

The dose-response curve obtained with VIP in control experiments was shifted significantly to the right after administration of the VIP analogue $(P<0.05, n=8$ in four animals at each dose level; Fig. 4). The fall in IASP after VIP $\left(1.5 \times 10^{10}\right.$ $\mathrm{mol} / \mathrm{kg}$ ) in control experiments was $42.8 \pm 5.2 \%$ (from 45.8 \pm 3.2 to $25.27 \pm 2.6 \mathrm{mmHg}$ ), and after [4CI-D-Phe ${ }^{6}, \mathrm{Leu}^{17}$ ] VIP it was $20.3 \pm 5.3 \%$ (from $48.21 \pm 3.6$ to $37.8 \pm 3.4 \mathrm{mmHg}$ ) ( $P$ $<0.05 ; n=8$ in four animals). This represents an antagonism of $52 \%$. The fall in IASP after the threshold dose of VIP (1.1 $\times 10^{-12} \mathrm{~mol} / \mathrm{kg}$ ) was $19.2 \pm 3.7 \%$ (from $61.0 \pm 2.9$ to $48.5 \pm 2$ $\mathrm{mmHg}$ ) and after [4CI-D-Phe ${ }^{6}$, $\mathrm{Leu}^{17}$ ] VIP, it was almost abolished to $1.9 \pm 1.6 \%$ (from $58.7 \pm 6.4$ to $57.5 \pm 6.2 \mathrm{mmHg}$ ) $(P$ $<0.05 ; n=8$ in four animals). This represents an antagonism of $90 \%$. The fall in IASP of $89.5 \pm 1.1 \%$ (from $55.6 \pm 2.0$ to $5.7 \pm 0.5 \mathrm{mmHg})$ after the MED of VIP $\left(1.8 \times 10^{-9} \mathrm{~mol} / \mathrm{kg}\right)$ was significantly antagonized to $56.1 \pm 3.8 \%$ (from $63.5 \pm 3.3$ to $27.5 \pm 2.6 \mathrm{mmHg})(P<0.05 ; n=8$ in four animals $)$. This represents an antagonism of $37 \%$.

In a separate series of experiments, the dose of [4CI-D$\left.\mathrm{Phe}^{6}{ }^{6} \mathrm{Leu}^{17}\right]$ VIP that antagonized the response of VIP (1.5 $\times 10^{-10} \mathrm{~mol} / \mathrm{kg}$ ) was found not to modify the inhibitory effects of isoproterenol $\left(2.9 \times 10^{-10} \mathrm{~mol} / \mathrm{kg}\right)$, adenosine $\left(7.9 \times 10^{-7}\right.$ $\mathrm{mol} / \mathrm{kg})$, and PHI $\left(6.0 \times 10^{-10} \mathrm{~mol} / \mathrm{kg}\right)$. In control experiments the fall in IASP with VIP, isoproterenol, adenosine, and PHI was $56.2 \pm 11.2,69.5 \pm 9.4,90.7 \pm 1.6$, and $56.1 \pm 14.9 \%$, respectively. In the presence of VIP antagonist these values were $12.2 \pm 6.9(P<0.05 ; n=4), 70.3 \pm 16.2,93.2 \pm 0.4$, and $67.2 \pm 16.0 \%$, respectively $(P>0.05 ; n=4)$.

The VIP antagonist, VIP analogue at a dose of $2.3 \times 10^{-7}$ $\mathrm{mol} / \mathrm{kg}$ (i.a.) by itself caused a transient fall in IASP of $33.8 \pm 6.2 \%$. This fall in IASP began within $13.4 \pm 2.2 \mathrm{~s}$ and lasted for $49.8 \pm 13.0 \mathrm{~s}$.

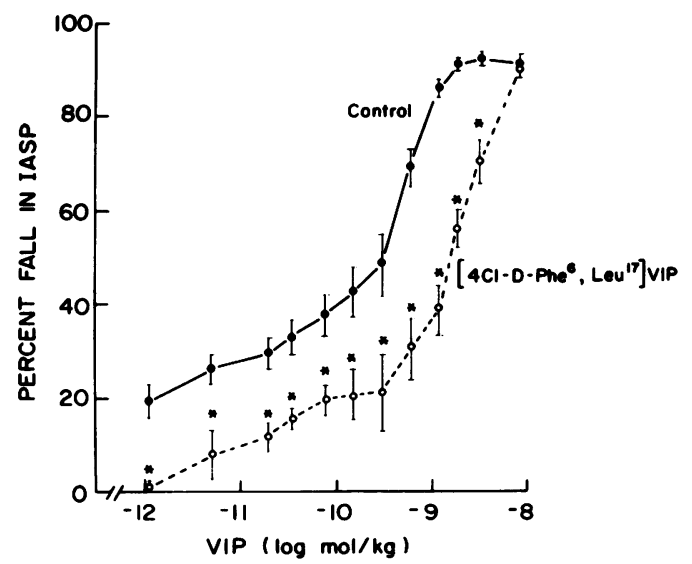

Figure 4. Influence of VIP antagonist [4CI-D-Phe ${ }^{6}, \mathrm{Leu}^{17}$ ] VIP on the fall in IASP caused by VIP. The antagonist caused a significant rightward shift in the entire dose-response curve of VIP. The calculated $D_{50}$ for VIP before and after the antagonist were $1.5 \times 10^{-10}$ and 2 $\times 10^{-9} \mathrm{~mol} / \mathrm{kg}(P<0.05 ; n=8$ in four animals, two observations in each animal at each dose level). 


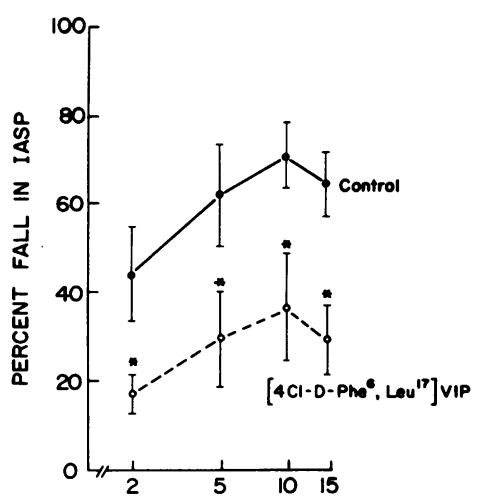

RECTAL BALLOON DISTENTION (ml)
Figure 5. Influence of VIP antagonist [4CI-D-

$\mathrm{Phe}^{6}$, $\mathrm{Leu}^{17}$ ] VIP on percent fall in IASP in response to varying volumes of rectal balloon distension. The VIP antagonist caused significant antagonism of the fall in IASP caused by all the volumes of rectal balloon distension tested $(P$ $<0.05 ; n=8$ in four animals, two observations in each animal at each volume of rectal balloon distension).

Influence of [4CI-D-Phe $\left.{ }^{6}, \mathrm{Leu}^{17}\right]$ VIP on the fall in IASP caused by balloon distension in the rectum. The fall in IASP caused by different volumes of rectal distension tested was significantly antagonized by the VIP antagonist $(P<0.05 ; n$ $=8$ in four animals; Fig. 5). The fall in IASP in response to 10 $\mathrm{ml}$ rectal distension in control experiments was $71.2 \pm 8.0 \%$ (from $42.6 \pm 3.3$ to $13.0 \pm 3.6 \mathrm{mmHg}$ ) and after [4CI-D$\mathrm{Phe}^{6}, \mathrm{Leu}^{17}$ ] VIP, it was $36.6 \pm 12.3$ (from $46.6 \pm 1.6$ to $30.9 \pm 6.3$ $\mathrm{mmHg})(n=8$ in four animals; $P<0.05$; Fig. 5). This represents an antagonism of $49 \%$. Fig. 6 illustrates an example of

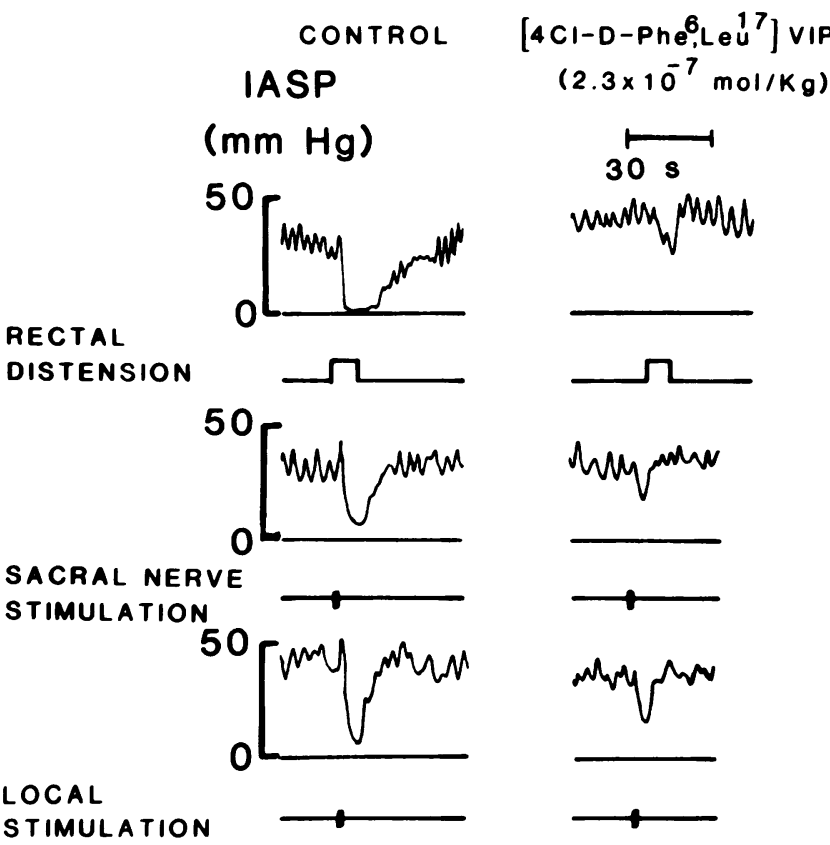

Figure 6. Examples of actual recordings showing the influence of VIP antagonist [4CI-D-Phe ${ }^{6}$, $\mathrm{Leu}^{17}$ ] VIP on the IAS responses to rectal distension ( $10 \mathrm{ml}$ for $8 \mathrm{~s}$ ), sacral nerve stimulation $(5 \mathrm{~mA} ; 0.5-\mathrm{ms}$ pulse duration; $5 \mathrm{~Hz}$ for 2-s train) and local intramural stimulation ( $5 \mathrm{~mA}$; $0.5-\mathrm{ms}$ pulse duration; $20 \mathrm{~Hz}$ for $2-\mathrm{s}$ train). The control responses to these stimuli showing IAS relaxation are shown on the left. The responses to these stimuli on IAS in the presence of VIP antagonist are shown on the right. As shown, VIP antagonist caused a significant reduction in the IAS relaxation in responses to these stimuli.

the inhibitory response of rectal balloon distension on the IAS before and after the VIP antagonist.

Influence of $\left[4 C I-D-P h e^{6}\right.$, Leu $\left.^{17}\right]$ VIP on fall in IASP caused by sacral nerve stimulation. At all frequencies tested, the VIP antagonist caused significant antagonism of the fall in IASP induced by electrical stimulation of the sacral nerve. Electrical stimulation of the sacral nerve at $5 \mathrm{~Hz}$ caused a fall in IASP of $70.9 \pm 6.0 \%$ (from $48.4 \pm 3.2$ to $14.8 \pm 3.2 \mathrm{mmHg}$ ) in control experiments. This response was significantly antagonized after [4CI-D-Phe ${ }^{6}, \mathrm{Leu}^{17}$ ] VIP to $36.7 \pm 8.8 \%$ (from $40.7 \pm 2.8$ to $26.8 \pm 4.7 \mathrm{mmHg})(P<0.05 ; n=12$ in four animals, three observations in each animal at each frequency; Fig. 7), as illustrated in Fig. 6. This represents an antagonism of $48 \%$.

Influence of VIP analogue [4CI-D-Phe ${ }^{6}$, Leu $\left.^{17}\right]$ VIP on fall in IASP caused by local intramural stimulation. The fall in IASP caused by local intramural stimulation at 20 and $40 \mathrm{~Hz}$ was significantly antagonized by the antagonist. The fall in IASP with 20 and $40 \mathrm{~Hz}$ of local intramural stimulation was $57.3 \pm 5.0 \%$ (from $45.3 \pm 2.6$ to $19.8 \pm 3.1 \mathrm{mmHg}$ ) and $60.6 \pm 7.7 \%$ (from $44.5 \pm 2.9$ to $19.1 \pm 4.8 \mathrm{mmHg}$ ), respectively, in control experiments. After [4CI-D-Phe ${ }^{6}, \mathrm{Leu}^{17}$ ] VIP, these responses were significantly antagonized to $31.6 \pm 7.4 \%$ (from $43.0 \pm 2.2$ to $29.8 \pm 3.7 \mathrm{mmHg}$ ) after $20 \mathrm{~Hz}$, and to $36.9 \pm 9.6 \%$ (from $41.8 \pm 3.7$ to $27 \pm 5.4 \mathrm{mmHg})$ after $40 \mathrm{~Hz}(P<0.05 ; n$ $=12$ in four animals, three observations in each animal at each frequency; Fig. 8), as illustrated in Fig. 6. This represents an antagonism of 45 and $39 \%$ respectively.

Influence of $G R F$ analogue (N-Ac-Tyr $\left.{ }^{1}, D-P h e^{2}\right)-G R F$ (1-29)-NH $\mathrm{NH}_{2}$ on fall in IASP caused by VIP and other agonists. Examination of different doses $\left(2.9 \times 10^{-9}\right.$ to $2.3 \times 10^{-8} \mathrm{~mol} /$ $\mathrm{kg}$ ) (i.a.) of GRF analogue suggested that $2.3 \times 10^{-8} \mathrm{~mol} / \mathrm{kg}$ caused a significant and consistent antagonism of VIP-induced fall in IASP (Table I). The amount of antagonism of VIP-induced fall in IASP by $\left(N\right.$-Ac-Tyr $\left.{ }^{1}, \mathrm{D}-\mathrm{Phe}^{2}\right)$-GRF (1-29)- $\mathrm{NH}_{2}$ was dependent on the dose of VIP used (Table I). GRF analogue at a dose that caused significant antagonism of the inhibitory effect of VIP on the IAS had no significant effect on the fall in IASP caused by different agonists.

In a separate series of experiments the fall in IASP in response to VIP $\left(1.5 \times 10^{-10} \mathrm{~mol} / \mathrm{kg}\right)$, isoproterenol $\left(2.9 \times 10^{-10}\right.$

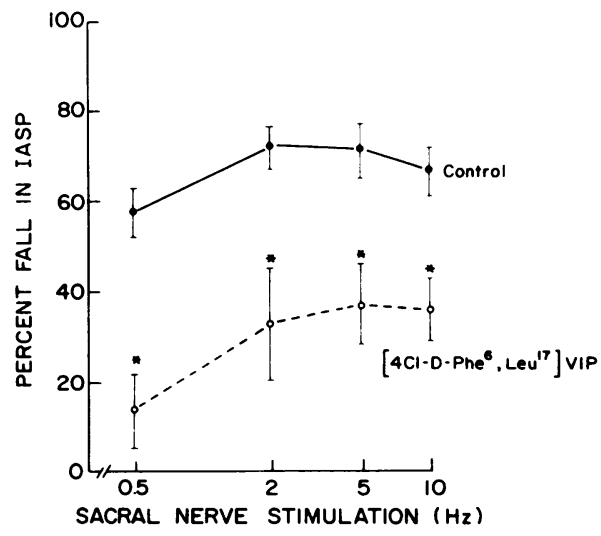

Figure 7. Influence of [4CI-D-Phe $\left.{ }^{6}, \mathrm{Leu}^{17}\right]$ VIP on percent fall in IASP caused by sacral nerve stimulation. Note that the VIP antagonist caused significant antagonism of fall in IASP caused by different frequencies of sacral nerve stimulation $(P<0.05 ; n=12$ in four animals, three observations in each animal at each frequency of stimulation). 
Figure 8. Influence of [4CI-D-Phe ${ }^{6}$, Leu $^{17}$ ] VIP on percent fall in IASP by local intramural stimulation. The fall in IASP-caused local stimulation examined at 20 and $40 \mathrm{~Hz}(5 \mathrm{~mA} ; 0.5$ ms pulse duration; 2 -s train) was significantly antagonized by VIP antagonist $\left(2.3 \times 10^{-7}\right.$ $\mathrm{mol} / \mathrm{kg}$, i.a. $)(P<0.05$; $n=12$ in four animals, three observations in each animal at different frequencies).

$\mathrm{mol} / \mathrm{kg})$, adenosine $\left(7.9 \times 10^{-7} \mathrm{~mol} / \mathrm{kg}\right)$, and PHI $\left(6.0 \times 10^{-10}\right.$

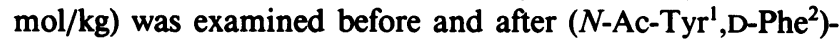
GRF (1-29)-NH $\mathrm{NH}_{2}$. The fall in IASP with these agonists before the antagonist was $68.5 \pm 9.7,74.8 \pm 8.8,90.2 \pm 5.6$, and $63.9 \pm 13.0 \%$, respectively. In the presence of the antagonist these values were $34.9 \pm 4.9,78.4 \pm 7.9,85.5 \pm 2.3$, and $62.5 \pm 7.4 \%$, respectively. The fall in IASP with VIP in the presence of the antagonist was significantly different $(P<0.05$; $n=4)$ while effects of other agonists were not significantly modified $(P>0.05 ; n=4)$.

The antagonism of VIP in causing a fall in IASP with a single dose of $2.3 \times 10^{-8} \mathrm{~mol} / \mathrm{kg}$ (i.a.) of $\left(N\right.$-Ac-Tyr $\left.{ }^{1}, \mathrm{D}-\mathrm{Phe}^{2}\right)$ GRF (1-29)- $\mathrm{NH}_{2}$ lasted $\sim 40$ min. However, this duration could be prolonged with the continuous infusion of GRF ana-

Table I. Influence of GRF analogue, (N-Ac-Tyr $\left.{ }^{1}, D-P h e^{2}\right)-$ $G R F(1-29)-\mathrm{NH}_{2}\left(2.3 \times 10^{-8} \mathrm{~mol} / \mathrm{kg}\right)$ on the Fall in IASP in Response to Exogenous VIP

\begin{tabular}{clcccc}
\hline VIP & & $\begin{array}{c}\text { Initial } \\
\text { pressure }\end{array}$ & $\begin{array}{c}\text { Final } \\
\text { pressure }\end{array}$ & $\begin{array}{c}\text { Fall in } \\
\text { pressure }\end{array}$ & $\begin{array}{c}\text { Percent } \\
\text { fall }\end{array}$ \\
\hline$m o l / k g$ & & $m m H g$ & $m m H g$ & $m m H g$ & $\%$ \\
$4.5 \times 10^{-12}$ & Control & $49 \pm 3$ & $38 \pm 2$ & $11 \pm 2$ & $22 \pm 3$ \\
& GRF analogue & $60 \pm 3$ & $60 \pm 3$ & 0 & $0^{*}$ \\
$1.8 \times 10^{-11}$ & Control & $40 \pm 3$ & $29 \pm 3$ & $11 \pm 3$ & $27 \pm 6$ \\
& GRF analogue & $49 \pm 6$ & $45 \pm 6$ & $3 \pm 1$ & $7 \pm 1^{*}$ \\
$3.6 \times 10^{-11}$ & Control & $39 \pm 1$ & $25 \pm 2$ & $14 \pm 2$ & $36 \pm 4$ \\
& GRF analogue & $34 \pm 1$ & $31 \pm 1$ & $3 \pm 1$ & $10 \pm 1^{*}$ \\
$7.5 \times 10^{-11}$ & Control & $39 \pm 2$ & $22 \pm 3$ & $17 \pm 2$ & $45 \pm 5$ \\
& GRF analogue & $33 \pm 2$ & $27 \pm 2$ & $6 \pm 1$ & $16 \pm 3^{*}$ \\
$1.5 \times 10^{-10}$ & Control & $39 \pm 2$ & $19 \pm 3$ & $19 \pm 2$ & $51 \pm 5$ \\
& GRF analogue & $37 \pm 3$ & $30 \pm 3$ & $7 \pm 1$ & $18 \pm 3^{*}$ \\
\multirow{2}{*}{$6 \times 10^{-10}$} & Control & $44 \pm 3$ & $14 \pm 2$ & $30 \pm 3$ & $68 \pm 4$ \\
& GRF analogue & $44 \pm 4$ & $26 \pm 4$ & $18 \pm 3$ & $42 \pm 6^{*}$ \\
$1.8 \times 10^{-9}$ & Control & $53 \pm 2$ & $6 \pm 1$ & $47 \pm 3$ & $87 \pm 1$ \\
& GRF analogue & $47 \pm 7$ & $17 \pm 3$ & $30 \pm 3$ & $64 \pm 2^{*}$ \\
$7.2 \times 10^{-9}$ & Control & $45 \pm 6$ & $4 \pm 1$ & $40 \pm 6$ & $90 \pm 1$ \\
& GRF analogue & $60 \pm 5$ & $4 \pm 1$ & $56 \pm 4$ & $94 \pm 1$ \\
& & & & & \\
\hline
\end{tabular}

Values expressed as mean $\pm \mathrm{SE}$ of $n=5$ in five animals.

* $P<0.05$; the difference between the values obtained during control and GRF analogue are significantly different.

logue $\left(5.7 \times 10^{-10} \mathrm{~mol} / \mathrm{kg}\right.$ per min). Administration of GRF analogue $\left(N\right.$-Ac-Tyr $\left.{ }^{1}, \mathrm{D}-\mathrm{Phe}^{2}\right)$-GRF $(1-29)-\mathrm{NH}_{2}\left(2.3 \times 10^{-8}\right.$ $\mathrm{mol} / \mathrm{kg}$ ) (i.a.) by itself caused a transient fall in IASP of $38.4 \pm 10.8 \%$. This fall in IASP with GRF analogue occurred within $14.4 \pm 3.2 \mathrm{~s}$ and lasted for $74.5 \pm 23 \mathrm{~s}$.

Influence of (N-Ac-Tyr',D-Phe $\left.e^{2}\right)-G R F(1-29)-\mathrm{NH}_{2}$ on IAS relaxation caused by balloon distension in the rectum. The fall in IASP with rectal distension was significantly antagonized by GRF analogue. These values denote significant antagonism of rectal distension-induced fall in IASP in the presence of GRF analogue $(P<0.05 ; n=15$ in five animals; Fig. 9$)$. The fall in IASP in response to $10 \mathrm{ml}$ rectal distension in control experiments was $71.2 \pm 5.9 \%$ (from $47.5 \pm 5.5$ to $13.0 \pm 7.2 \%$ (from $36.3 \pm 3.0$ to $23.7 \pm 4.4 \mathrm{mmHg})(P<0.05 ; n=15$ in five animals, three observations in each animal at each volume). This represents an antagonism of $46 \%$.

Influence of GRF analogue on fall in IASP produced by sacral nerve stimulation. GRF analogue caused a significant antagonism of fall in IASP caused by sacral nerve stimulation at all the frequencies examined. With $5 \mathrm{~Hz}$, the IASP fall was $78.4 \pm 3.1 \%$ (from $39.3 \pm 5.3$ to $7.6 \pm 1.0 \mathrm{mmHg}$ ) in controls and

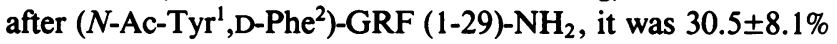
(from $42.0 \pm 3.7$ to $30.6 \pm 5.4 \mathrm{mmHg})(P<0.05 ; n=15$ in five animals; Fig. 9). This represents an antagonism of $61 \%$.

Influence of GRF analogue, ( $\left.N-A c-T y r^{l}, D-P h e^{2}\right)-G R F$ (1-29)- $\mathrm{NH}_{2}$ on fall in the IASP caused by local intramural stimulation. The fall in IASP caused by local intramural stimulation was also significantly antagonized by GRF analogue

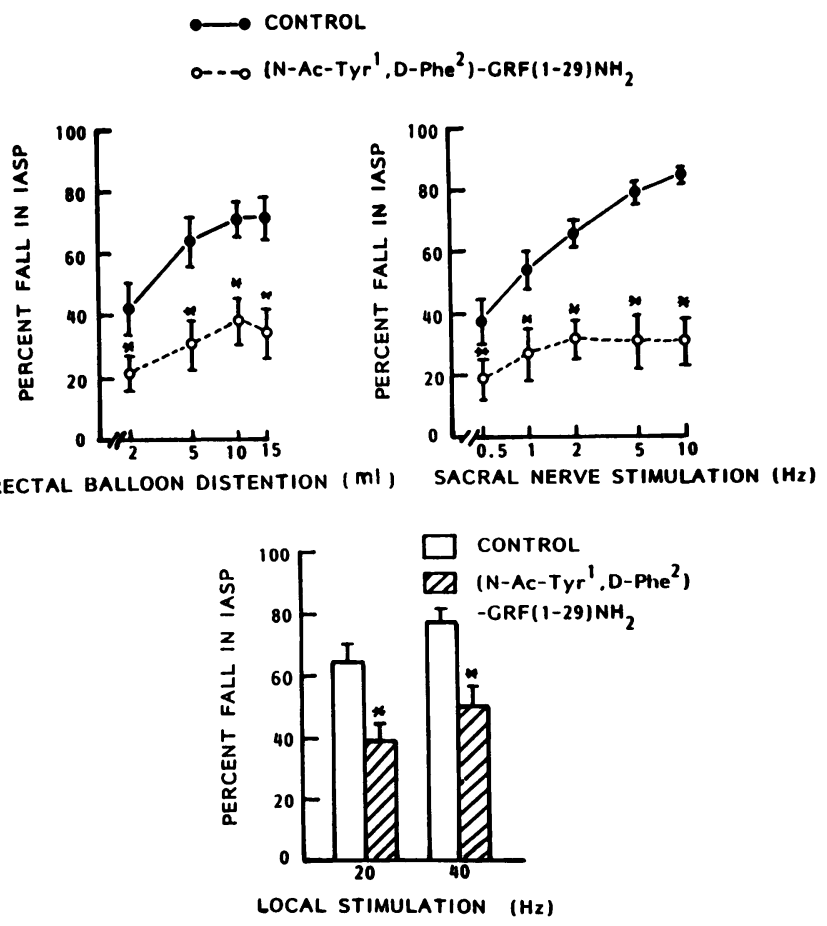

Figure 9. Influence of $\left(\mathrm{N}-\mathrm{Ac}-\mathrm{Tyr}^{1}, \mathrm{D}-\mathrm{Phe}^{2}\right)$-GRF (1-29)- $\mathrm{NH}_{2}$ on percent fall in IASP caused by rectal balloon distension, sacral nerve stimulation, and local intramural stimulation. Note that the VIP antagonist caused significant antagonism of fall in IASP caused by different neural stimuli at the different intensities of stimulation tested $(P<0.05 ; n=15$ in five animals, three observations in each animal at each level of stimulation). 
(Fig. 9) $(P<0.05 ; n=15$ in five animals). The fall in IASP after 20 and $40 \mathrm{~Hz}$ was $64.5 \pm 5.9 \%$ (from $36.7 \pm 2.9$ to $10.9 \pm 1.0$ $\mathrm{mmHg}$ ) and $77.4 \pm 4.4 \%$ (from $42.9 \pm 1.7$ to $8.6 \pm 0.8 \mathrm{mmHg}$ ), respectively. After the GRF analogue, it was antagonized to $38.9 \pm 5.5 \%$ (from $36.5 \pm 2.4$ to $23.1 \pm 3.3 \mathrm{mmHg}$ ) and $50.3 \pm 6.0 \%$ (from $38.8 \pm 1.7$ to $20.4 \pm 3.2 \mathrm{mmHg}$ ), respectively. This represents an antagonism of $40 \%$ and $35 \%$, respectively.

Influence of two different doses of GRF analogue, ( $N$-ACTyr',D-Phe $\left.{ }^{2}\right)-G R F(1-29)-\mathrm{NH}_{2}$ on fall in the IASP caused by $V I P$. In order to see whether the antagonism of fall in IASP caused by different stimuli with GRF analogue was dose dependent, we compared the influence of two doses, $2.3 \times 10^{-8}$ and $9.2 \times 10^{-8} \mathrm{~mol} / \mathrm{kg}$ (i.a.), respectively, of GRF analogue on different stimuli. We first examined the effect of different doses of VIP in causing a fall in IASP before and after two doses of GRF analogue. GRF analogue caused dose-dependent antagonism of the fall in IASP by VIP (Fig. 10). The dose of VIP $\left(1.5 \times 10^{-10} \mathrm{~mol} / \mathrm{kg}\right)$ which caused a fall in IASP of $45.3 \pm 2.3 \%$ (from $33.3 \pm 1.8$ to $16.3 \pm 1.6 \mathrm{mmHg}$ ) was antagonized to $27.6 \pm 5.4 \%$ (from $35.0 \pm 1.7$ to $25.5 \pm 3.1 \mathrm{mmHg}$ ) and $18.3 \pm 1.1 \%$ (from $29.2 \pm 5.8$ to $23.7 \pm 4.4 \mathrm{mmHg}$ ) by $2.3 \times 10^{-8}$ and $9.2 \times 10^{-8} \mathrm{~mol} / \mathrm{kg}$ of GRF analogue, respectively. Examination of the three dose-response curves with VIP revealed that both doses of GRF analogue caused incremental and significant rightward shifts in the control curve.

Influence of two different doses of GRF analogue, (N-AC$\left.T^{T} r^{l}, D-P h e^{2}\right)-G R F(1-29)-\mathrm{NH}_{2}$ on fall in IASP produced by rectal distension. The fall in IASP after rectal balloon distension was further antagonized by increasing doses of GRF analogue (Fig. 11). After $5 \mathrm{ml}$ the fall of IASP in the control was $81.0 \pm 2.1 \%$ (from $32.6 \pm 1.3$ to $6.1 \pm 0.5 \mathrm{mmHg}$ ); this was antagonized to $66.2 \pm 8.4 \%$ (from $44.1 \pm 5.9$ to $14.1 \pm 3.4 \mathrm{mmHg}$ ) and $54.1 \pm 2.9 \%$ (from $27.5 \pm 1.7$ to $12.5 \pm 1.0 \mathrm{mmHg}$ ) after 2.3 $\times 10^{-8}$ and $9.2 \times 10^{-8} \mathrm{~mol} / \mathrm{kg}$ of GRF analogue, respectively $(P<0.05)$. As can be seen in Fig. 11 the increasing antagonism to the fall in IASP after balloon distension with higher doses of

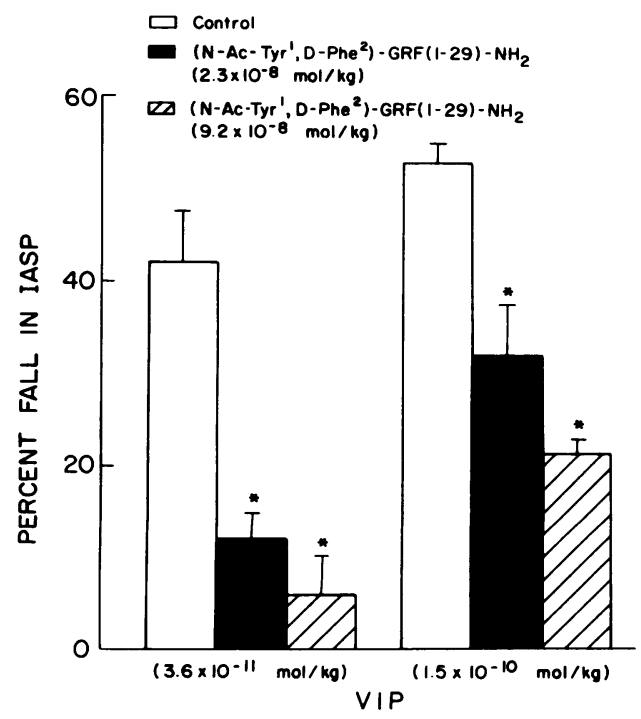

Figure 10. Influence of two different doses of VIP antagonist ( $\mathrm{N}$-Ac$\mathrm{Tyr}^{1}$,D-Phe $\left.{ }^{2}\right)$-GRF (1-29)-NH $\mathrm{NH}_{2}$ on the fall in IASP caused by two doses of VIP $\left(3.6 \times 10^{-11}\right.$ and $\left.1.5 \times 10^{-10} \mathrm{~mol} / \mathrm{kg}\right)$. Note that the VIP antagonist caused significant antagonism of the inhibitory responses of VIP in a dose-dependent manner.

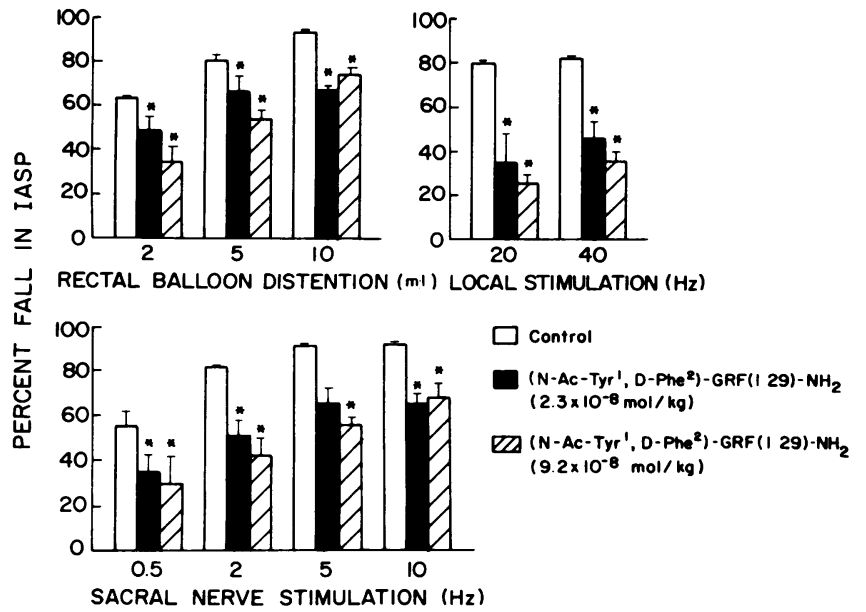

Figure 11. Influence of VIP antagonist ( $N$-Ac- $\left.\mathrm{Tyr}^{1}, \mathrm{D}-\mathrm{Phe}^{2}\right)$-GRF $(1-29)-\mathrm{NH}_{2}$ on the percent fall in IASP in response to rectal balloon distension $(2,5$, and $10 \mathrm{ml})$, sacral nerve stimulation $(0.5,2,5$, and $10 \mathrm{~Hz}$ with $5 \mathrm{~mA} ; 0.5-\mathrm{ms}$ pulse duration and 2-s train) and local intramural stimulation ( 20 and $40 \mathrm{~Hz}$ with $5 \mathrm{~mA} ; 0.5-\mathrm{ms}$ pulse duration and 2-s train). Note that both doses of the antagonist caused significant antagonism of the fall in IASP in response to different stimuli.

GRF analogue was more evident at the lower volumes of rectal balloon distension.

Influence of two different doses of $G R F$ analogue on the fall in IASP produced by sacral nerve stimulation. Increasing doses of GRF analogue antagonized further the IASP response to sacral nerve stimulation (Fig. 11). As with balloon distension, this was more evident at the lower frequencies of electrical stimulation. At $5 \mathrm{~Hz}$ the IASP fall in controls was $92.3 \pm 0.3 \%$ (from $32.8 \pm 1.4$ to $2.5 \pm 0.2 \mathrm{mmHg}$ ) and was antagonized to $65.9 \pm 6.5 \%$ (from $44.3 \pm 1.9$ to $15.1 \pm 3 \mathrm{mmHg}$ ) and $57.7 \pm 3.9 \%$ (from $23.5 \pm 0.6$ to $10.0 \pm 1.1 \mathrm{mmHg}$ ) after $2.3 \times 10^{-6}$ and 9.2 $\times 10^{-6} \mathrm{~mol} / \mathrm{kg}$ GRF analogue, respectively $(P<0.05)$.

Influence of two different doses of GRF analogue, $(N-A C$ Tyr $\left.{ }^{l}, D-P h e^{2}\right)-G R F(1-29)-\mathrm{NH}_{2}$ on the fall in IASP produced by local stimulation. As can be seen in Fig. 11, increasing doses of GRF analogue further antagonized the response of IASP to local stimulation. The IASP fall after $20 \mathrm{~Hz}$ was $80.2 \pm 0.9$ (from $42.1 \pm 1.8$ to $8.3 \pm 0.6 \mathrm{mmHg}$ ) in controls and was antagonized to $35.8 \pm 12.0 \%(42.5 \pm 1.1$ to $27.5 \pm 5.4 \mathrm{mmHg})$ and $26.6 \pm 2.1 \%$ (from $25.8 \pm 4.1$ to $19.1 \pm 3.6 \mathrm{mmHg}$ ) after 2.3 $\times 10^{-8}$ and $9.2 \times 10^{-8} \mathrm{~mol} / \mathrm{kg} \mathrm{GRF}$ analogue, respectively $(P$ $<0.05$ ).

Influence of VIP antagonists on the fall in resting tension of IAS smooth muscle strips in response to VIP and EFS. EFS and VIP caused a fall in IAS tension in in vitro strips. The inhibitory responses to EFS were frequency dependent, and those to VIP were dose dependent (Figs. 12 and 13). Both

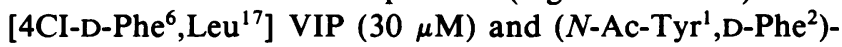
GRF (1-29)- $\mathrm{NH}_{2}(10 \mu \mathrm{M})$ caused a significant rightward shift in the VIP dose-response and EFS frequency-response curves (Figs. 12 and $13 ; P<0.05$ ).

\section{Discussion}

The present studies suggest that VIP acts as an inhibitory neurotransmitter of intramural neurons in IAS relaxation in re- 


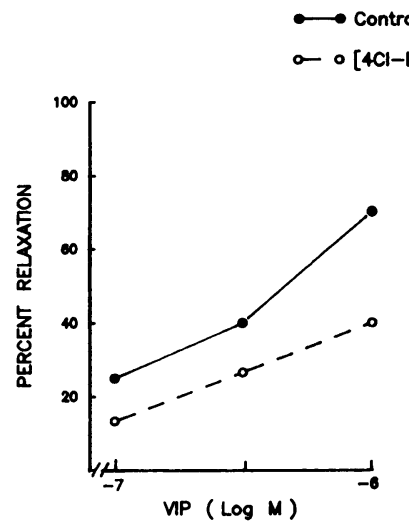

$$
\text { -Phe6.Lou }{ }^{17} \mathrm{MP}
$$

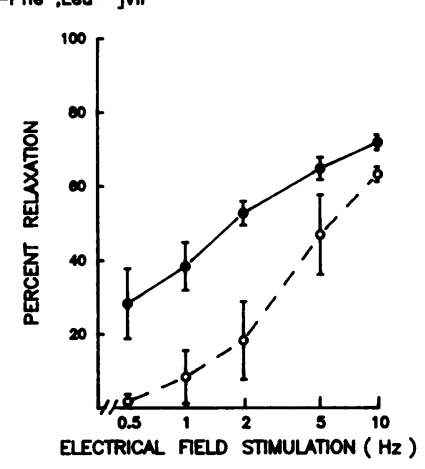

Figure 12. Influence of [4CI-D-Phe ${ }^{6}$, Leu $^{17}$ ] VIP on percent relaxation in the resting IAS tension in in vitro studies. The figure shows the inhibitory responses of different doses of VIP (left) and different frequencies of EFS (right) on resting IAS tension before and after VIP analogue $(30 \mu \mathrm{M})$. The inhibitory responses are represented as percent relaxation of resting IAS tension. VIP antagonist caused a significant rightward shift in the percent relaxation curves obtained with different doses of VIP and different frequencies of EFS $(P<0.05)$.

sponse to the rectoanal reflex in the opossum. This conclusion is supported by the following findings. VIP is a potent relaxant of IAS smooth muscle. The relaxant effect of VIP is exerted by its action directly at the smooth muscle since the inhibitory response of VIP on the IAS was TTX resistant. The direct inhibitory action of VIP on the IAS smooth muscle strips has also been shown before $(1,3,21)$. However, further support for the conclusion that VIP may act as the inhibitory neurotransmitter in the IAS comes from the present investigation which used selective VIP antagonists: [4CI-D-Phe ${ }^{6} \mathrm{Leu}^{17}$ ] VIP (15) and $\left(N\right.$-Ac-Tyr $\left.{ }^{1}, \mathrm{D}-\mathrm{Phe}^{2}\right)$-GRF $(1-29)-\mathrm{NH}_{2}(16)$. The VIP analogue has been shown to selectively inhibit VIP-stimulated amylase secretion and cAMP elevation in in vitro preparations of guinea pig exocrine pancreas (15). The GRF analogue has

$$
\begin{aligned}
& \multimap \text { Control } \\
& \sim \odot\left(N-A c-T_{y}{ }^{1}, D-P h e^{2}\right)-G R F(1-29) N_{2}
\end{aligned}
$$
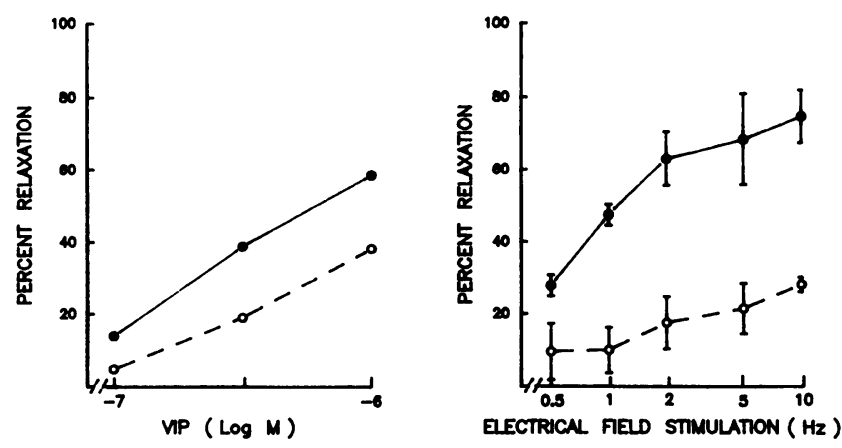

Figure 13. Influence of $\left(\mathrm{N}-\mathrm{Ac}-\mathrm{Tyr}^{1}, \mathrm{D}-\mathrm{Phe}^{2}\right)$-GRF (1-29)-NH $\mathrm{NH}_{2}$ on percent fall in the resting IAS tension in in vitro strips. Different doses of VIP (left) and frequencies of electrical field stimulation (right) caused incremental relaxation of resting IAS tension in control experiments. The GRF analogue $(10 \mu \mathrm{M})$ caused significant rightward shifts in both the dose-response curves obtained with VIP and EFS $(P<0.05)$. been shown to antagonize adenylate cyclase stimulation in response to VIP receptor activation in the rat pancreatic plasma membranes (16). In both systems these antagonists were shown to behave as selective and competitive antagonists to VIP receptors. In our experiments, VIP antagonists in doses that produced significant antagonism of fall in IASP by VIP caused significant impairment in IAS relaxation in response to rectal balloon distension (which mimics rectoanal inhibitory reflex), thus providing additional support for our hypothesis.

These studies also suggest that IAS relaxation in response to rectoanal reflex is mediated through the release of VIP from intramural myenteric inhibitory neurons. Such inhibitory neurons appear to lie in the sacral inhibitory pathway. The support for this hypothesis comes from the following findings. VIP antagonists which caused antagonism of rectal balloon distension-mediated IAS relaxation also antagonized the fall in IASP in response to preganglionic sacral nerve stimulation and local intramural stimulation. We have previously shown that the fall in IASP by local intramural stimulation is due to activation of the intramural inhibitory neurons (2). The findings are further substantiated by our in vitro experiments in the IAS strips. In such studies, the antagonism of the fall in IAS tension caused by EFS and VIP in the presence of VIP antagonists suggests the release of VIP from the intramural inhibitory neurons. Interestingly, previous studies have suggested the presence of VIP immunoreactivity in intramural myenteric neurons of the IAS region $(22,23)$.

The conclusion of the present investigation is in agreement with that of the LES studies $(11,14)$ where VIP has been suggested to act as an inhibitory neurotransmitter. Furthermore, a number of studies have shown the presence of VIP. containing nerve fibers in different regions of the gut $(24,25)$ and the release of VIP from the venous effluent draining the rectal region in response to pelvic nerve stimulation $(9,10,13)$ and rectal distension (9) in cats and pigs.

Our studies further suggest that VIP may not be the only neurotransmitter involved in the IAS relaxation by the rectoanal reflex since the VIP antagonists in the doses that almost abolished the fall in IASP caused by lower doses of VIP failed to abolish the IAS relaxation in response to lower levels of neural stimuli. It is possible that another inhibitory neurotransmitter is released in addition to VIP and is partially responsible for IAS relaxation. In that case, it would be important to further examine the role of such a substance in IAS relaxation. Purinergic substances have been shown to act as inhibitory neurotransmitters in a variety of tissues (6). Our recent studies however rule out the participation of purinergic agents as the inhibitory neurotransmitters in IAS relaxation (Rattan, S., and R. Shah, manuscript in preparation).

The present studies also show that [4CI-D-Phe ${ }^{6}, \mathrm{Leu}^{17}$ ] VIP and $\left(N-\mathrm{Ac}^{-} \mathrm{Tyr}^{1}, \mathrm{D}-\mathrm{Phe}^{2}\right)$-GRF (1-29)- $\mathrm{NH}_{2}$ can be used successfully as VIP antagonists in in vivo as well as in vitro studies. Whether these antagonists act as competitive antagonists in vivo experiments is not clearly known. However, a number of factors point to that effect. First, the antagonists caused a parallel shift in the VIP dose-response curve showing fall in IASP. Secondly, the maximal fall in IASP by VIP in control experiments was still obtained in the presence of VIP antagonists although the dose of VIP required to do so was increased many fold. Thirdly, when higher doses of the VIP antagonist $\left(N-\right.$ Ac-Tyr $\left.^{1}, \mathrm{D}-\mathrm{Phe}^{2}\right)$-GRF $(1-29)-\mathrm{NH}_{2}$ were used, they produced incremental antagonism of the fall in IASP by VIP. 
Furthermore, the antagonists were selective in antagonizing the inhibitory responses of VIP on the IAS without modifying the responses to isoproterenol, adenosine, and PHI.

The findings of the present investigation suggest that VIP plays a significant role as an inhibitory neurotransmitter in rectoanal reflex-mediated IAS relaxation. However, further studies seeking electrophysiologic and biochemical correlates for the inhibitory responses of rectoanal reflex, sacral nerve stimulation, local intramural stimulation, and VIP need to be performed. Information relating to the inhibitory neurotransmitter involved in IAS relaxation would lead to a better understanding of the pathophysiology of anorectal incontinence and constipation, as they relate to the reflex control mechanisms of the anorectal region.

\section{Acknowledgments}

The authors thank Drs. R. Goyal, Chafiq Moummi, A. Sengupta, and R. Shah for their helpful criticism, and Dr. B. Ransil for his help with the statistical analysis and computer resources. The authors also thank Mr. J. Kaczmarek for his technical assistance, and Mr. L. McGee and Ms. P. Prahl for typing the manuscript.

This work was supported by U.S. Public Health Service grant DK-35385 and DK-31092 and Electrophysiology Core Grant DK-34854 from the National Institutes of Health.

\section{References}

1. Burleigh, D. E., A. D'Mello, and A. G. Parks. 1979. Responses of isolated human internal anal sphincter to drugs and electrical field stimulation. Gastroenterology. 77:484-490.

2. Rattan, S., and R. Shah. 1987. Influence of sacral nerves on the internal anal sphincter of the opossum: nature of synaptic transmission. Am. J. Physiol. 253:G345-G350.

3. Biancani, P., J. H. Walsh, and J. Behar. 1985. Vasoactive intestinal polypeptide: a neurotransmitter for relaxation of the rabbit internal anal sphincter. Gastroenterology. 89:867-874.

4. Adebarjo, A. O., N. Ambache, and J. Verney. 1976. The inhibitory transmission to the internal anal sphincter. Br. J. Pharmacol. 56:392-393.

5. Bouvier, M., and J. Gonella. 1981. Nervous control of the internal anal sphincter of the cat. J. Physiol. (Lond.). 310:457-469.

6. Burnstock, G. 1986. The non-adrenergic non-cholinergic nervous system. Arch. Int. Pharmacodyn. Ther. 280:1-15.

7. Goyal, R. K., and S. Rattan. 1975. Nature of the vagal inhibitory innervation to the lower esophageal sphincter. J. Clin. Invest. 55:1119-1126.

8. Said, S. I. 1986. Vasoactive intestinal peptide. J. Endocrinol. Invest. 9:191-200.

9. Fahrenkrug, J., U. Haglund, M. Jodal, O. Lundgreen, I. Olbe, and O. B. Schaffalitzki de Muckadell. 1978. Nervous release of va- soactive intestinal polypeptide in the gastrointestinal tract of cats: possible physiological implications. J. Physiol. (Lond.). 284:291-305.

10. Fahrenkrug, J., M. Galbo, J. J. Holst, and O. B. Schaffalitsky de Muckadell. 1978. Influence of the autonomic nervous system on the release of vasointestinal polypeptide from the porcine gastrointestinal tract. J. Physiol. (Lond.). 280:405-422.

11. Goyal, R. K., S. Rattan, and S. Said. 1980. VIP as a possible neurotransmitter of non-cholinergic, non-adrenergic inhibitory neurones. Nature (Lond.). 288:378-380.

12. Grider, J. R., M. B. Cable, K. N. Bitar, S. I. Said, and G. M. Makhlouf. 1985. Vasoactive intestinal peptide: relaxant neurotransmitter in tenia coli of the guinea pig. Gastroenterology. 89:36-42.

13. Andersson, P. O., S. R. Bloom, and J. Järhealt. 1983. Colonic motor and vascular responses to pelvic nerve stimulation and their relation to local peptide release in the cat. J. Physiol. (Lond.). 334:293-307.

14. Biancani, P., J. H. Walsh, and J. Behar. 1984. Vasoactive intestinal polypeptide: a neurotransmitter for lower esophageal sphincter relaxation. J. Clin. Invest. 73:963-967.

15. Pandol, S. J., K. Dharmasathaphorn, M. S. Schoeffield, W. Vale, and J. Rivier. 1986. Vasoactive intestinal peptide receptor antagonist [4CI-D-Phe ${ }^{6}$,Leu ${ }^{17}$ ] VIP. Am. J. Physiol. 250:G553-G557.

16. Waelbroeck, M., P. Robberecht, D. M. Coy, J. C. Camus, P. D. Neef, and J. Christophe. 1985. Interaction of growth hormone-releasing factor (GRF) and 14 GRF analogs with vasoactive intestinal peptide (VIP) receptors of rat pancreas. Discovery of ( $N$-Ac- $\left.\mathrm{Tyr}^{1}, \mathrm{D}-\mathrm{Phe}^{2}\right)$ GRF (1-29)- $\mathrm{NH}_{2}$ as a VIP antagonist. Endocrinology. 116:2643-2649.

17. Culver, P. J., and S. Rattan. 1986. Genesis of anal canal pressures in the opossum. Am. J. Physiol. 251:G765-G771.

18. Christensen, J., G. A. Rick, B. A. Robison, M. J. Stiles, and M. A. Wix. 1983. Arrangement of the myenteric plexus throughout the gastrointestinal tract of the opossum. Gastroenterology. 85:890-899.

19. Christensen, J., and G. A. Rick. 1985. Nerve cell density in submucous plexus throughout the gut of the cat and opossum. Gastroenterology. 89:1064-1069.

20. Zar, J. H. 1974. Multiple regression and correlation. In Biostatistical analysis. Prentice-Hall, Inc., Englewood Cliffs, NJ. 252-280.

21. Neya, T., T. Yamasato, M. Takaki, M. Mizutani, and S. Nakayama. 1981. Excitatory and inhibitory effects of vasoactive intestinal polypeptide (VIP) on the isolated jejunum and internal anal sphincter in the guinea pig. Biomed. Res. 2:398-403.

22. Alumets, J., J. Fahrenkrug, R. Håkanson, O. Schaffalitzky de Muckadell F. Sundler, and R. Uddman. 1979. A rich VIP nerve supply is characteristic of sphincters. Nature (Lond.). 280:155-156.

23. McGregor, G. P., A. E. Bishop, M. A. Blank, N. D. Christofides, Y. Yiangou, J. M. Polak, and S. R. Bloom. 1984. Comparative distribution of vasoactive intestinal polypeptide (VIP), substance P and PHI in the enteric sphincters. Experientia (Basel). 40:469-471.

24. Christensen, J., T. M. Williams, J. Jew, and T. M. D’Orisio. 1987. Distribution of vasoactive intestinal polypeptide immunoreactive structures in the opossum esophagus. Gastroenterology. 92:10071018.

25. Costa, M., J. B. Furness, and I. J. Liewellyn-Smith. 1987. Histochemistry of the enteric nervous system. In Physiology of the Gastrointestinal Tract. L. R. Johnson, editor. Raven Press, New York. 1-40. 